\section{IMPROVEMENT IN FUNCTIONAL RECOVERY OF THE ISOLATED GUINEA PIG HEART AFTER HYPERKALEMIC REPERFUSION WITH ADENOSINE}

The aim of this study was to examine the effect of initial hyperkalemic reperfusion (HKR), with and without added adenosine, on coronary flow, myocardial function, and endothelium-dependent and endothelium-independent coronary vascular function. Cardioplegic arrest was induced in $\mathbf{4 0}$ isolated guinea pig hearts by infusing oxygenated cardioplegic (high in potassium ion) Krebs solution for 5 minutes. Hearts were then stored at room temperature for 3.5 hours. On reperfusion, hearts were divided into four groups of 10 hearts each: control, reperfusion with regular Krebs solution (4.6 $\mathrm{mmol} / \mathrm{L}$ potassium chloride); base hyperkalemic reperfusion, initial reperfusion with $37^{\circ} \mathrm{C}$ oxygenated, cardioplegic Krebs solution for 5 minutes; hyperkalemic reperfusion with addition of $1 \mathrm{mmol} / \mathrm{L}$ adenosine during HKR; and hyperkalemic reperfusion with addition of $5 \mathrm{mmol} / \mathrm{L}$ adenosine. Coronary reserve (adenosine bolus $2 \mathrm{mmol} / \mathrm{L}$ ) and responses to acetylcholine (1 $\mu \mathrm{mol} / \mathrm{L}$ ) and nitroprusside $(100 \mu \mathrm{mol} / \mathrm{L})$ were examined before and after ischemia and reperfusion. Flow did not return to preischemic values in any group after reperfusion. Adenosine treatment during initial reperfusion increased coronary flow (percentage of baseline \pm standard error of the mean) from $57 \% \pm$ $4 \%$ in control and $\mathbf{4 5 \%} \pm 3 \%$ in hearts with hyperkalemic reperfusion to $79 \% \pm$ $3 \%$ and $83 \% \pm 5 \%$ in hearts with hyperkalemic reperfusion also treated with, respectively, $1 \mathrm{mmol} / \mathrm{L}$ adenosine and $5 \mathrm{mmol} / \mathrm{L}$ adenosine $(p<0.05)$. At 30 and 60 minutes of reperfusion, however, flow remained elevated only in the group treated with $5 \mathrm{mmol} / \mathrm{L}$ adenosine. Coronary reserve and responses to acetylcholine and nitroprusside were equivalently depressed in all groups after reperfusion. Recovery of left ventricular systolic and diastolic function was improved in all groups after hyperkalemic reperfusion $(54 \% \pm 4 \%$ of preischemic value) compared with control $(39 \% \pm 3 \%)$, and recovery was further enhanced in the group treated with $5 \mathrm{mmol} / \mathrm{L}$ adenosine $(60 \% \pm 4 \%)$. In this ex vivo model, hyperkalemic reperfusion improved myocardial function after cardioplegic arrest and the addition of $5 \mathrm{mmol} / \mathrm{L}$ adenosine improved coronary flow. Adenosine may counteract the potassium chloride-induced vasoconstriction that occurs during hyperkalemic reperfusion and may thus improve coronary flow and myocardial function. Postischemic depression of endothelium-dependent or endothelium-independent vascular functions, however, was not alleviated by hyperkalemic reperfusion with or without adenosine. (J Thorac Cardiovasc Surg 1996;111:74-84)

Helmut Habazettl, MD, Barbara W. Palmisano, MD, Bernhard M. Graf, MD, David L. Roerig, PhD, Zeljko J. Bosnjak, PhD, and David F. Stowe, MD, PhD, Milwaukee, Wis.
From the Anesthesiology Research Laboratory, and the Departments of Anesthesiology and Physiology, Cardiovascular Research Center, The Medical College of Wisconsin, and the Veterans Affairs Medical Center, Milwaukee, Wis.

Received for publication Dec. 5, 1994.

Accepted for publication April 19, 1995.

Supported by Deutsche Forschungsgemeinschaft, grant Ha 1651/ 5-1 (H. H.) and VA Merit Grant 8204-04P (D. F. S.).

Address for reprints: Heimut Habazettl, MD, Institute for Surgical Research, University of Munich, Marchioninistrasse 15, 81366 Munich, Germany.

$12 / 1 / 65887$
W arm cardioplegic blood reperfusion was long ago demonstrated to reduce reperfusion damage in a canine model of ischemia and reperfusion. ${ }^{1,2}$ It was found that by lowering calcium and increasing $\mathrm{pH}$, potassium, and osmolarity in the initial $500 \mathrm{ml}$ of blood reperfusate, left ventricularperformance as measured by left ventricular pressure and maximum pressure changes $\left(\mathrm{dp} / \mathrm{dt}_{\text {max }}\right)$, which was depressed by about $40 \%$ in control hearts, could be nearly restored. Arresting the heart was thought 
to reduce oxygen demand during this initial reperfusion period, making the delivered oxygen available for reparative work and replenishment of energy stores before the onset of cardiac pump function. A whole series of consecutive experimental studies, aimed at further improving the method, corroborated the beneficial effects of warm cardioplegic blood reperfusion, ${ }^{3-7}$ which seemed to be effective in human beings as well as in animals. 8,9

Although the benefits of hyperkalemic reperfusion (HKR) for recovery of myocardial function are well documented, data concerning coronary vascular function are less conclusive. Potassium is a well known vasoconstrictor and is regularly used in isolated vessel preparations to constrict vessel rings. A high potassium concentration reduces myocardial oxygen demand by reducing cardiac work, but it also limits oxygen delivery by restricting coronary flow so that this ratio is reduced. ${ }^{10}$ Flow during HKR was not reported in Follette and colleagues' initial study, ${ }^{2}$ and oxygen supply, as well as demand, may decrease during HKR. Regional blood flow was measured in the beating working heart before and after ischemia and reperfusion, however, and a marked decrease (almost 25\%) in coronary flow was observed in the group receiving only the highpotassium reperfusate. ${ }^{2}$ In human beings, coronary flow during HKR was found to either decrease ${ }^{8}$ or increase, ${ }^{9}$ possibly depending on previous damage to the coronary vasculature. Moreover, the effect of metabolically mediated flow changes could not be determined because coronary sinus oxygen was not measured. In this study, we investigated the effect of HKR on coronary flow and myocardial oxygen balance in an ex vivo model of cardiac ischemia and reperfusion. The isolated, Langendorff-perfused guinea pig heart preparation allows careful control of extrinsic variables and precise on-line measurement of global coronary flow and oxygen extraction during all phases of the experiment. The preparation is also suitable for testing endothelium-dependent and endothelium-independent vascular responsiveness and release of metabolic byproducts. Our aim was to improve recovery of myocardial function by augmenting coronary flow during HKR through the addition of the coronary vasodilator adenosine to the initial cardioplegic reperfusate. An improvement in the oxygen nutrient supply caused by adenosine, coupled with depression of contractility by high potassium during HKR, might result in improved cardiac performance after ischemia.

\section{Methods}

After Animal Studies Committee approval was obtained, 40 albino English short-haired guinea pigs (250 to $350 \mathrm{gm}$ ) were injected intraperitoneally with $20 \mathrm{mg}$ ketamine and $1000 \mathrm{U}$ heparin. The animals were decapitated when unresponsive to noxious stimuli. All animals received humane care in compliance with the "Principles of Laboratory Animal Care" formulated by the National Society for Medical Research and the "Guide for the Care and Use of Laboratory Animals" published by the National Institutes of Health. Our methods have been published in detail. ${ }^{10,12}$ After thoracotomy, the aorta was cannulated distal to the aortic valve and the venae cavae and pulmonary artery were cut. Each heart was immediately perfused retrogradely through the aorta and excised. All hearts were perfused at a controlled perfusion pressure of $55 \mathrm{~mm} \mathrm{Hg}$, as measured at the aortic root. The perfusate, a modified Krebs-Ringer solution, was filtered in line $(5 \mu \mathrm{m}$ pore size, Astrodisc; Gelman Scientific, Ann Arbor, Mich.) and contained the following: $137 \mathrm{mmol} / \mathrm{L}$ sodium ion, $4.5 \mathrm{mmol} / \mathrm{L}$ potassium ion, $1.2 \mathrm{mmol} / \mathrm{L} \mathrm{mag-}$ nesium ion, $2.5 \mathrm{mmol} / \mathrm{L}$ calcium ion, $134 \mathrm{mmol} / \mathrm{L}$ chloride ion, $15.5 \mathrm{mmol} / \mathrm{L}$ bicarbonate, $1.2 \mathrm{mmol} / \mathrm{L}$ dihydrogen phosphate, $11.5 \mathrm{mmol} / \mathrm{L}$ glucose, $2 \mathrm{mmol} / \mathrm{L}$ pyruvate, 16 $\mathrm{mmol} / \mathrm{L}$ mannitol, $0.05 \mathrm{mmol} / \mathrm{L}$ ethylenediaminetetraacetic acid, and 5 U/L insulin. Cardioplegic Krebs solution has an equivalent osmolarity, $300 \mathrm{mosm} / \mathrm{L}$, but differs in concentrations of sodium ion $(123 \mathrm{mmol} / \mathrm{L})$, potassium ion $(28 \mathrm{mmol} / \mathrm{L})$, and calcium ion $(1.25 \mathrm{mmol} / \mathrm{L})$. Perfusate and bath temperatures were maintained at $37^{\circ} \mathrm{C}$ by means of a thermostatically controlled water circulator (VWR 1130; Preston Industries Inc., Niles, Ill.). Both solutions were equilibrated with a gas mixture of $97 \%$ oxygen and $3 \%$ carbon dioxide. Left ventricular pressure (LVP) was measured isovolumetrically with a transducer (DTX; Spectramed, Oxnard, Calif.) connected to a flexible, saline solution-filled latex balloon (Hugo Sachs Electronik, KG, March-Hugstetten, Germany) inserted into the left ventricle through the mitral valve by way of a cut in the left atrium. Balloon volume was adjusted to maintain an end-diastolic LVP of $6 \mathrm{~mm} \mathrm{Hg}$. Positive and negative maximum instantaneous pressure changes $(\mathrm{dP} /$ $\mathrm{dt}_{\text {max }}$ ) were determined electronically with an analog differentiator.

Electrograms were recorded with pairs of bipolar electrodes (plastic-coated silver, diameter $125 \mu \mathrm{m}$ ) placed on the right atrial appendage and on the right ventricular pulmonary conus. The electrode signals were amplified and displayed continuously on a digital oscilloscope (Nicolet 310; Nicolet Instrument Corporation, Madison, Wis.) and audially monitored. Electrogram intervals for determination of heart rate and atrioventricular conduction time were measured on-line by digital timer systems that allowed instantaneous interval and rate analyses. Ventricular tachycardia was defined by the presence of uniform or multiform ventricular waveforms and faster ventricular than atrial rate. Ventricular fibrillation was defined by the presence of erratic activity in the ventricular electrogram and by the absence of pressure generation by the left ventricle.

Coronary flow was measured on-line with an ultrasonic flow probe (T106 small animal blood flowmeter; Tran- 
sonic Systems, Inc., Ithaca, N.Y.). Coronary sinus effluent was collected by a cannula placed in the right ventricle through the pulmonary artery after ligature of the venae cavae. Coronary outflow oxygen tension $\left(\mathrm{Po}_{2}\right.$ was measured continuously on-line (Instech 203B; Instech Laboratories, Plymouth Meeting, $\mathrm{Pa}$.). The temperature-controlled Clark electrode was recalibrated periodically by means of a bypass circuit with perfusate gassed with room air. Both inflow and outflow $\mathrm{PO}_{2}$ were verified off-line with a self-calibrating analyzer system (ABL-300; Radiometer, Copenhagen, Denmark). Oxygen delivery was calculated from the inflow $\mathrm{Po}_{2}$ times oxygen solubility $(24 \mu \mathrm{l} / \mathrm{ml}$ saline solution $/ 760 \mathrm{~mm} \mathrm{Hg}$ ) times coronary flow per gram dry heart tissue weight. Myocardial oxygen consumption $\left(\mathrm{MVO}_{2}\right)$ was calculated as follows: oxygen solubility times coronary flow per gram times the difference between inflow and outflow $\mathrm{Po}_{2}$. Percentage of oxygen extraction was calculated as 100 times the difference between inflow and outflow $\mathrm{PO}_{2}$ divided by inflow $\mathrm{Po}_{2}$. Efficiency of oxygen utilization in performing contractile work was defined as systolic LVP times heart rate divided by $\mathrm{MVO}_{2}$.

All directly measured electronic signals were displayed on a high-resolution eight-channel recorder (Astro-Med Dash 8; Astro-Med Inc., West Warwick, R.I.), taperecorded for back-up (Vetter D1; Vetter Co., Rebersburg, $\mathrm{Pa}$. ), and stored on floppy discs by a personal computer (model 310; Hewlett-Packard Co., Palo Alto, Calif.) equipped with a 12-bit analog-to-digital converter sampling at $10 \mathrm{~Hz}$ (AD 200; Infotek Systems, Anaheim, Calif.). Each value is the mean of a 10 -second data segment that was visually inspected to ensure absence of artifacts.

The time constant of isovolumic pressure decline, $\tau$, which reflects the time required for LVP to fall about one third of its value at peak $-\mathrm{dP} / \mathrm{dt}_{\max }$, was calculated as described previously. ${ }^{13}$ Peak $-\mathrm{dP} / \mathrm{dt}_{\max }$ was used as zero time, and pressure was recorded for $60 \mathrm{msec}$ per beat for 3 to 4 consecutive beats. The natural $\log$ of pressure at time $t\left(\ln \mathrm{P}_{\mathrm{t}}\right)$ was plotted against the $t$-axis, and $\tau$ was defined as the negative reciprocal of the slope of the linear section of the curve, according to the equation $\ln \mathrm{P}_{\mathrm{t}}=$ $-\mathrm{t} / \tau+\ln \mathrm{P}_{0}$, where $P_{t}$ is LVP at time $t$ and $P_{o}$ is LVP at peak $-\mathrm{dP} / \mathrm{dt}$. This method has been successfully applied to the Langendorff-perfused guinea pig heart by using a fluid-filled left ventricular balloon system connected to a pressure transducer by a short tube of stiff polyethylene material. ${ }^{14}$

Protocol and statistical analysis. After completion of the preparation and a 10-minute period of stabilization, adenosine $(0.2 \mathrm{ml}$ of a $2 \mathrm{mmol} / \mathrm{L}$ stock solution) was injected to detertmine maximal coronary reserve. Only hearts that increased flow by $100 \%$ or more were included. After 30 minutes of further stabilization, baseline values of all measured variables were obtained and hearts were assigned to one of four groups: control $(n=10)$, HKR $(n=10)$, HKR with $1 \mathrm{mmol} / \mathrm{L}$ adenosine (HKR $+\mathrm{A} 1, n=10$ ), and $\mathrm{HKR}$ with $5 \mathrm{mmol} / \mathrm{L}$ adenosine $(\mathrm{HKR}+\mathrm{A} 5, n=10)$.

Cardioplegic arrest was induced in all hearts by perfusing oxygenated cardioplegic Krebs solution for 5 minutes at room temperature $\left(23^{\circ} \mathrm{C}\right)$. The left ventricular balloon was then deflated, and hearts remained unperfused and submerged in the same cardioplegic Krebs solution at room temperature for 3.5 hours. Control hearts were then reperfused with regular $37^{\circ} \mathrm{C}$ Krebs solution for $90 \mathrm{~min}$ utes. Hearts in the HKR group were initially reperfused with $37^{\circ} \mathrm{C}$ oxygenated cardioplegic Krebs solution for 5 minutes before reperfusion with regular Krebs solution. In hearts in the HKR $+\mathrm{A} 1$ and HKR $+\mathrm{A} 5$ groups, 1 and 5 $\mathrm{mmol} / \mathrm{L}$ adenosine, respectively, were added to the cardioplegic Krebs solution during the initial 5 minutes of reperfusion only. The left ventricular balloon was reinflated to $6 \mathrm{~mm} \mathrm{Hg}$ end-diastolic pressure at 15 minutes of reperfusion, and all hearts were bolus-infused with lidocaine $(0.05 \mathrm{ml}$ of a $1 \%$ solution) at 20 minutes of reperfusion to convert any hearts not already in sinus rhythm. Subsequently, lidocaine was only given to those hearts that reverted to ventricular fibrillation. Coronary flow was measured during induction of cardioplegia, during hyperkalemic reperfusion, and at 1, 2, 3, 4, 5, 15, 30, and 60 minutes of reperfusion. Measurements of all other variables were made at 30 and 60 minutes of reperfusion. Before and after ischemia and reperfusion, coronary reserve (adenosine bolus, $2 \mathrm{mmol} / \mathrm{L}$ ) and responses to acetylcholine $(1 \mu \mathrm{mol} / \mathrm{L})$ and nitroprusside $(100 \mu \mathrm{mol} / \mathrm{L})$ perfusion were assessed. Before ischemia and at 10 and 60 minutes of reperfusion, coronary effluent was collected and immediately frozen at $-70^{\circ} \mathrm{C}$ for later analysis of adenosine and inosine levels by high-pressure liquid chromatography. ${ }^{15}$

All data are expressed as mean \pm standard error of the mean. Statistical differences among groups were obtained by two-way analysis of variance for repeated measurements (SuperANOVA; Abacus Concepts Inc., Berkeley, Calif.). Differences were considered significant at $p<$ 0.05 .

\section{Results}

Coronary flow. Baseline coronary flow, measured in milliliters per minute, and dry tissue weight, measured in grams, did not differ among groups (Fig. 1). In all groups, flow remained essentially unchanged during induction of cardioplegic arrest. In control hearts, peak reflow within 1 minute of reperfusion reached $85 \% \pm 8 \%$ of $52 \pm 2 \mathrm{ml} /$ $\mathrm{min} / \mathrm{gm}$ preischemic flow and stabilized at $57 \% \pm$ $4 \%$ after 3 minutes. In hearts in the HKR group, peak reflow was $93 \% \pm 7 \%$ of $58 \pm 3 \mathrm{ml} / \mathrm{min} / \mathrm{gm}$ preischemic flow but stabilized at $45 \% \pm 3 \%$ until the end of the 5-minute hyperkalemic reperfusion. During perfusion with regular Krebs solution, coronary flow reached $58 \% \pm 2 \%$ of baseline within 5 minutes and remained at this level until 60 minutes of reperfusion. In hearts in the $\mathrm{HKR}+\mathrm{A} 1$ group, in which $1 \mathrm{mmol} / \mathrm{L}$ adenosine was present during the 5 minutes of HKR, peak reflow slightly exceeded preischemic baseline flow $(112 \% \pm 7 \%$ of $57 \pm 3$ $\mathrm{ml} / \mathrm{min} / \mathrm{gm}$ basal flow). At the end of HKR, flow had stabilized at $79 \% \pm 3 \%$ of the preischemic value. 


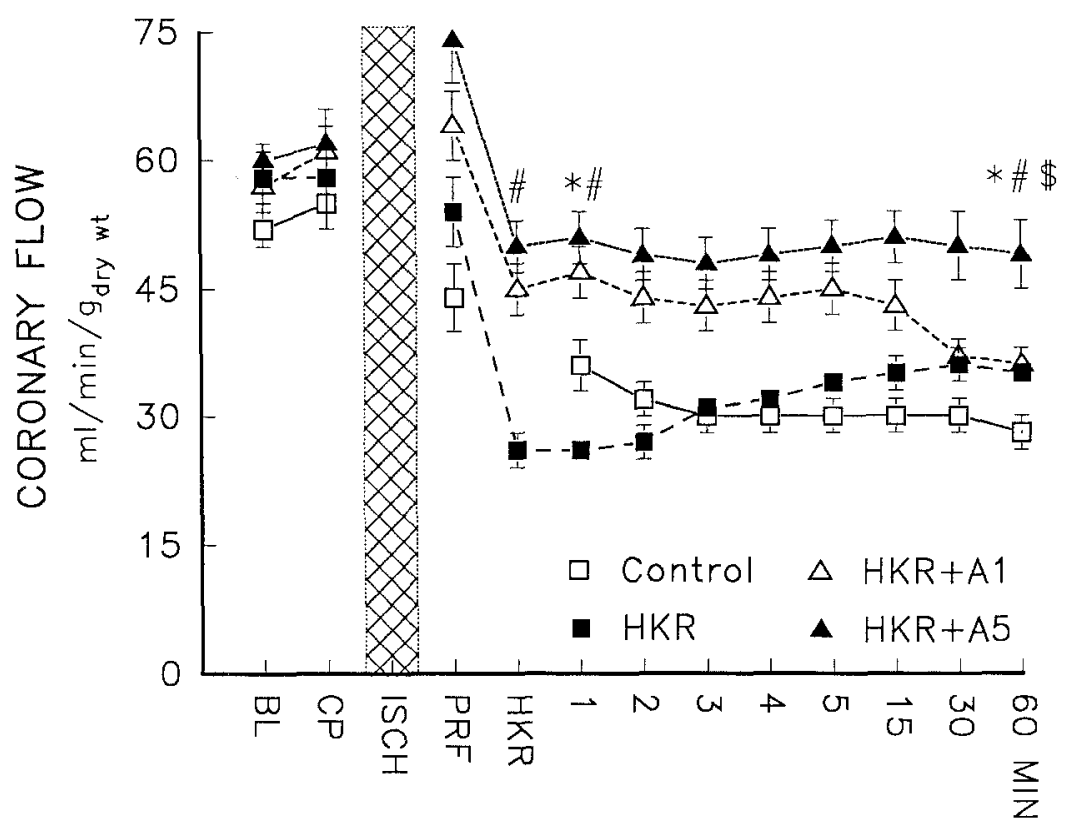

Fig. 1. The time course of coronary flow (in milliliters per minute per gram dry weight) is illustrated for four groups: control, HKR, HKR +A1, and HKR + A5. Measurements were taken before ischemia and reperfusion at baseline $(B L)$ and at the end of 5 minutes of perfusion with cardioplegic Krebs solution $(C P)$. After 210 minutes of ischemia $(I S C H)$, further measurements were obtained at peak reflow ( $P R F)$, the end of the 5 minutes of initial HKR, and after 1,2,3,4,5, 15, 30, and 60 minutes of reperfusion after the start of perfusion with regular Krebs solution. For better identification of single data points, the initial 15 minutes of reperfusion were stretched on the $x$-axis scale. Means \pm standard error of the mean. Symbols indicate $p$ values: ${ }^{*}, p<0.05$ vs control; \#, $p<0.05$ vs HKR; $\$, p<0.05$ vs HKR + A1.

Subsequently, flow slowly decreased to $76 \% \pm 5 \%$ and $65 \% \pm 3 \%$ at 15 and 30 minutes, respectively, but did not change thereafter $(64 \% \pm 3 \%$ at 60 minutes). Reperfusion with $5 \mathrm{mmol} / \mathrm{L}$ adenosine in hyperkalemic Krebs solution did not further increase peak reflow $(123 \% \pm 9 \%$ of the $60 \pm 2$ $\mathrm{ml} / \mathrm{min} / \mathrm{gm}$ baseline flow), nor did it affect steadystate perfusion at the end of HKR $(83 \% \pm 5 \%$ of initial flow). In contrast to hearts in the HKR+A1 group, however, coronary flow did not decrease during perfusion with regular Krebs solution without adenosine and it remained significantly less depressed $(83 \% \pm 5 \%$ and $81 \% \pm 6 \%$ at 30 and 60 minutes, respectively) compared with flows in all other groups.

Heart rate and cardiac rhythm. Baseline heart rate was about 230 beats/min in all four groups and increased slightly (by $5 \%$ to $20 \%$ ) on reperfusion. There were no differences among groups. Most of the hearts were dysrhythmic or fibrillated on reperfusion. After 60 minutes, only $20 \%$ of control hearts but more than $50 \%$ of the hearts treated with HKR performed at stable sinus rhythm, defined as fewer than five ventricular extrasystoles or periods of ventricular tachycardia per minute. In all hearts, hemodynamic and metabolic measurements were obtained during periods of sinus rhythm.

Left ventricular systolic and diastolic functions. Left ventricular contractile function was assessed by measuring isovolumetric $\mathrm{LVP}$ and $\mathrm{dP} / \mathrm{dt}_{\max }$. In this preparation, preload and afterload factors are held constant. In control hearts ischemic arrest and 60 minutes of reperfusion decreased developed (systolic minus diastolic) LVP (LVDP) and $\mathrm{dP} / \mathrm{dt}_{\max }$ to $39 \% \pm 3 \%$ and $45 \% \pm 3 \%$ of preischemic values, respectively. HKR significantly improved both parameters (LVDP $54 \% \pm 4 \% ; \mathrm{dP} / \mathrm{dt}_{\max } 62 \% \pm 5 \%$ ). Addition of $1 \mathrm{mmol} / \mathrm{L}$ adenosine to the initial cardioplegic reperfusate had no additional effect on recovery of left ventricular contractile function. Addition of $5 \mathrm{mmol} / \mathrm{L}$ adenosine to the cardioplegic reperfusate, however, further increased LVDP and $\mathrm{dP} / \mathrm{dt}_{\max }(60 \% \pm 4 \%$ and $78 \% \pm 8 \%$, respectively; Fig. 2). Left ventricular diastolic function was assessed by determining $-\mathrm{dP} / \mathrm{dt}_{\max }$, which reflects events that occur very early during LVP decline, and 

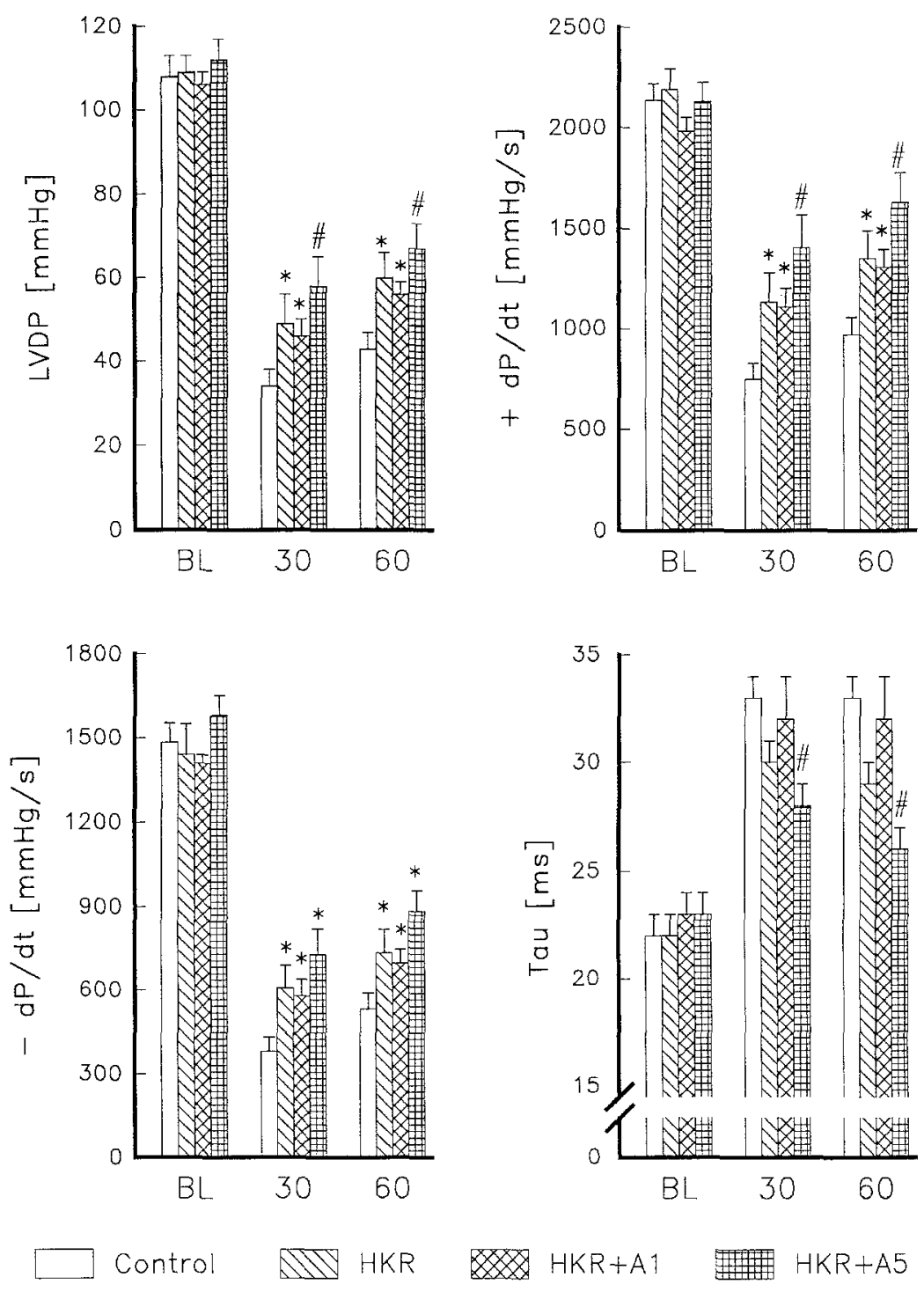

Fig. 2. The baseline data and the data for 30 and 60 minutes of reperfusion are given for LVDP, $+\mathrm{dP} / \mathrm{dt}_{\max }$ $(+d P / d t),-\mathrm{dP}_{\mathrm{dd}} \mathrm{t}_{\max }(-d P / d t)$, and $\tau(T a u)$. Left ventricular systolic and diastolic functions were markedly depressed after ischemia and reperfusion. Recovery of left ventricular function was improved by HKR alone and was further enhanced by addition of adenosine to the initial cardioplegic reperfusate. Means \pm standard error of the mean. Symbols indicate $p$ values: *, $p<0.05$ vs control; \#, $p<0.05$ vs control and HKR.

by determining $\tau$, which represents later events in the course of isovolumetric LVP decrease. In control hearts, $-\mathrm{dP} / \mathrm{dt}_{\max }$ decreased to $35 \% \pm 3 \%$ of $-1483 \pm 70 \mathrm{~mm} \mathrm{Hg} / \mathrm{sec}$ before cardioplegic arrest. HKR improved $-\mathrm{dP} / \mathrm{dt}_{\max }$ throughout the reperfusion period $(52 \% \pm 5 \%$ of the preischemic values at 60 minutes). Addition of 1 or $5 \mathrm{mmol} / \mathrm{L}$ adenosine had no significant effect on recovery of $-\mathrm{dP} / \mathrm{dt}_{\max }$. The $\tau$ value increased to $149 \% \pm 5 \%$ of baseline in control hearts after 60 minutes of reperfusion and did not statistically differ in hearts in either HKR or $\mathrm{HKR}+\mathrm{A} 1$ groups. Only the high concentration of adenosine in $\mathrm{HKR}+\mathrm{A} 5$ hearts significantly reduced the time constant of relaxation, to $116 \% \pm 5 \%$ of baseline (Fig. 2).

Oxygen metabolism. $\mathrm{MVO}_{2}$ decreased to $60 \% \pm$ $3 \%$ of baseline after 60 minutes of reperfusion in control hearts but was maintained significantly better in hearts in the HKR $(81 \% \pm 5 \%), \mathrm{HKR}+\mathrm{A} 1$ $(80 \% \pm 3 \%)$ and HKR + A5 $(89 \% \pm 8 \%)$ groups 

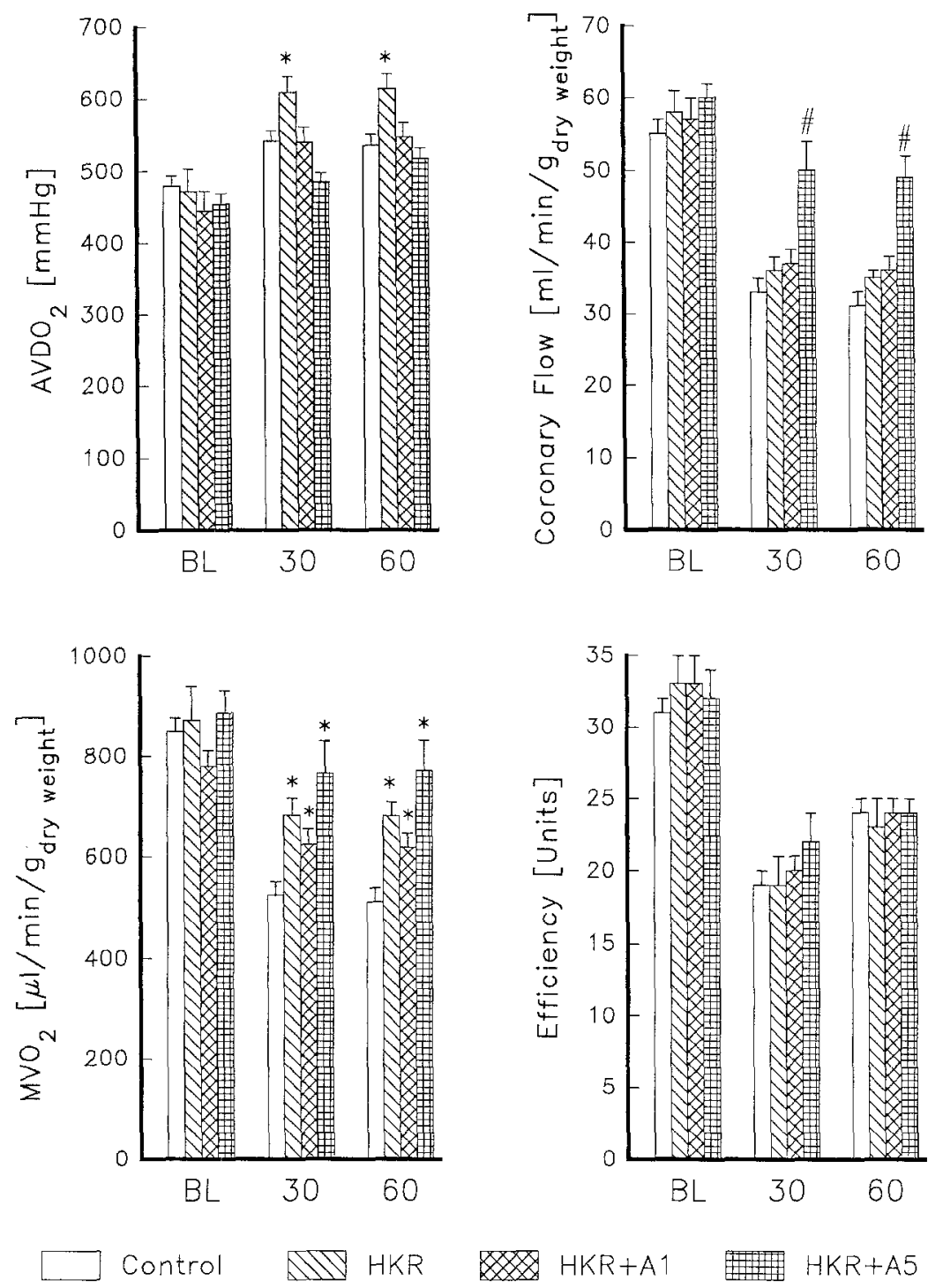

Fig. 3. The baseline data and the data at 30 and 60 minutes of reperfusion are given for the arterial to coronary venous oxygen difference $\left(A V \mathrm{DO}_{2}\right)$, coronary flow, $\mathrm{MVO}_{2}$, and the efficiency of oxygen utilization (efficiency). In control hearts, coronary flow was depressed to a degree similar to that of $\mathrm{MVO}_{2}$, suggesting an essentially intact oxygen balance. $\mathrm{HKR}$ increased $\mathrm{MVO}_{2}$ with no effect on flow, resulting in an increased oxygen extraction $\left(\mathrm{AVDO}_{2}\right)$. Addition of $5 \mathrm{mmol} / \mathrm{L}$ adenosine to the initial reperfusate increased flow and reduced $\mathrm{AVDO}_{2}$ to nearly baseline values. Efficiency remained equivalently depressed in all groups. Means \pm standard error of the mean. Symbols indicate $p$ values: ${ }^{*}, p<0.05$ vs control; $\#, p<0.05$ vs control, HKR, and HKR $+\mathrm{A} 1$.

(Fig. 3). Arterial-venous oxygen difference, which in this preparation with constant arterial $\mathrm{Po}_{2}$ also reflects oxygen extraction, increased in all groups but was significantly higher in hearts in the HKR group $(133 \% \pm 7 \%)$ than in control hearts $(111 \% \pm$ $3 \%)$ or hearts in the HKR +A5 group $(116 \% \pm 7 \%$; Fig. 3). The efficiency of the myocardium in converting consumed oxygen into mechanical work was equally decreased in all groups, to about $75 \%$ of baseline (Fig. 3).

Coronary reserve and vascular function. Before ischemia and reperfusion, coronary reserve, as evaluated by bolus injection of adenosine, amounted to well above $100 \%$ of baseline flow in all groups. After ischemia and reperfusion, coronary reserve was equally depressed in all groups, to only a $30 \%$ 


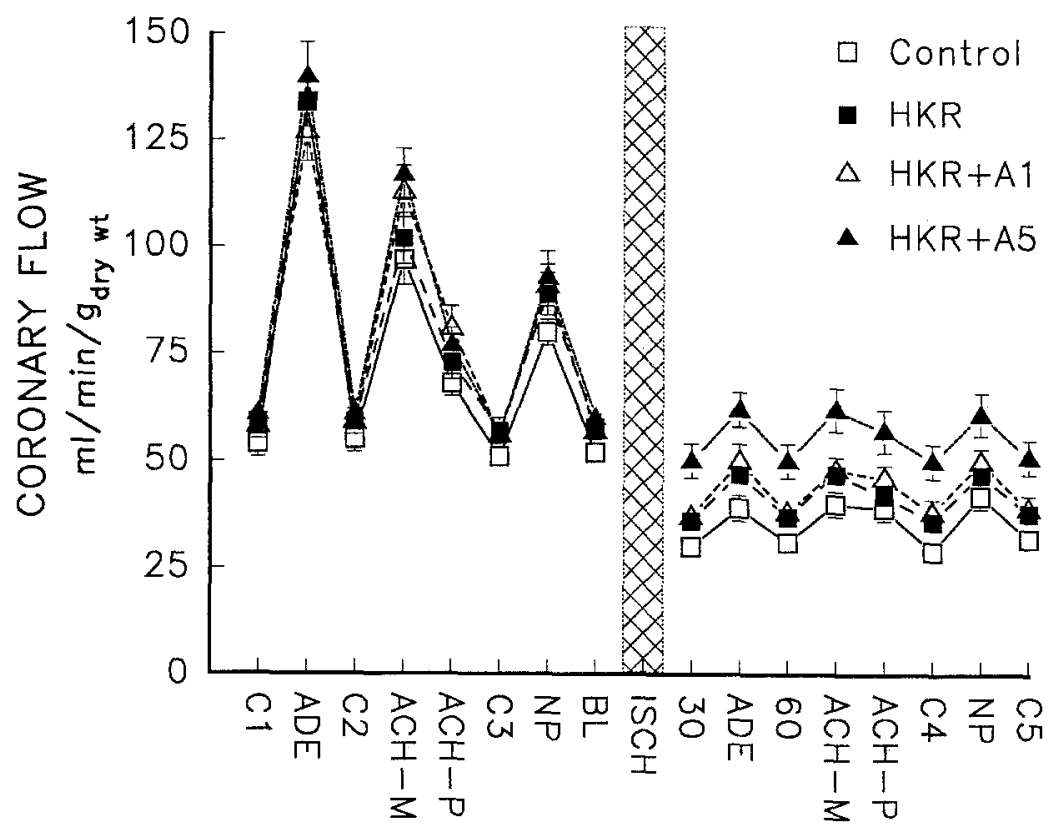

Fig. 4. Flow responses to coronary vasodilators before and after cardioplegic arrest and reperfusion. $C 1$ through $C 5$, Resting flow immediately before the respective vasodilator stimulation; $A D E, 2 \mathrm{mmol} / \mathrm{L}$ adenosine bolus; $A C H-M$, maximal flow response to acetylcholine infusion $(1 \mu \mathrm{mol} / \mathrm{L}) ; A C H-P$, steady-state flow during acetylcholine infusion and pacing the heart at the rate before infusion of the vasodilator; $N P$, nitroprusside $(100$ $\mu \mathrm{mol} / \mathrm{L}) ; B L$, baseline; 30 and 60 , respective periods of reperfusion in minutes; $I S C H$, ischemia (210-minute period). The increased postischemic basal flow in the HKR + A5 group did not result in improved responses to the vasodilators. Means \pm standard error of the mean. All stimulations caused statistically significant flow increases; all postischemic responses were significantly less pronounced than respective preischemic responses.

increase above the depressed postischemic resting flow. Postischemic flow responses to perfusion with nitroprusside and acetylcholine were similarly depressed in all groups (Fig. 4). The increased postischemic resting flow in hearts in the $\mathrm{HKR}+\mathrm{A} 5$ group had no effect on the respective flow responses.

Adenosine and inosine levels. Because adenosine and inosine concentrations were not determined in all experiments, data from hearts in the control and HKR groups, which did not differ between groups, were pooled for analysis. As shown in Fig. 5, inosine concentrations increased dramatically on reperfusion but approached baseline values after $60 \mathrm{~min}$ utes of reperfusion in all groups. Adenosine in coronary effluent increased only slightly in hearts in the control, HKR, and HKR +A1 groups at 10 minutes of reperfusion. The pronounced increase of adenosine in the HKR + A5 group, to almost 2000 $\mathrm{nmol} / \mathrm{L}$, mainly reffects the results of a single experiment in which adenosine increased from 2 to 9350 $\mathrm{nmol} / \mathrm{L}$. This is in contrast to more moderate increases from 18 to $405 \mathrm{nmol} / \mathrm{L}$ in the remaining hearts in the HKR + A5 group. At 60 minutes of reperfusion, adenosine levels were significantly elevated only in hearts in the HKR + A5 group.

\section{Discussion}

We used a model of cardioplegic arrest and reperfusion in isolated perfused guinea pig hearts to demonstrate the following: (1) Compared with normal Krebs solution reperfusion, HKR improved recovery of myocardial function but not of coronary flow. (2) Addition of $5 \mathrm{mmol} / \mathrm{L}$ adenosine during only the initial 5 minutes of hyperkalemic reperfusion significantly increased coronary flow and additionally enhanced myocardial function for up to 60 minutes of reperfusion. (3) The postischemic coronary flow responses to both endothelium-dependent and endothelium-independent vasodilators were similarly depressed in all groups.

The finding of improved myocardial function after HKR confirms the results of Follette and coworkers, ${ }^{1,2}$ who first described the beneficial effects of warm cardioplegic blood reperfusion in dogs. Because this group added potassium to the reperfusate without 


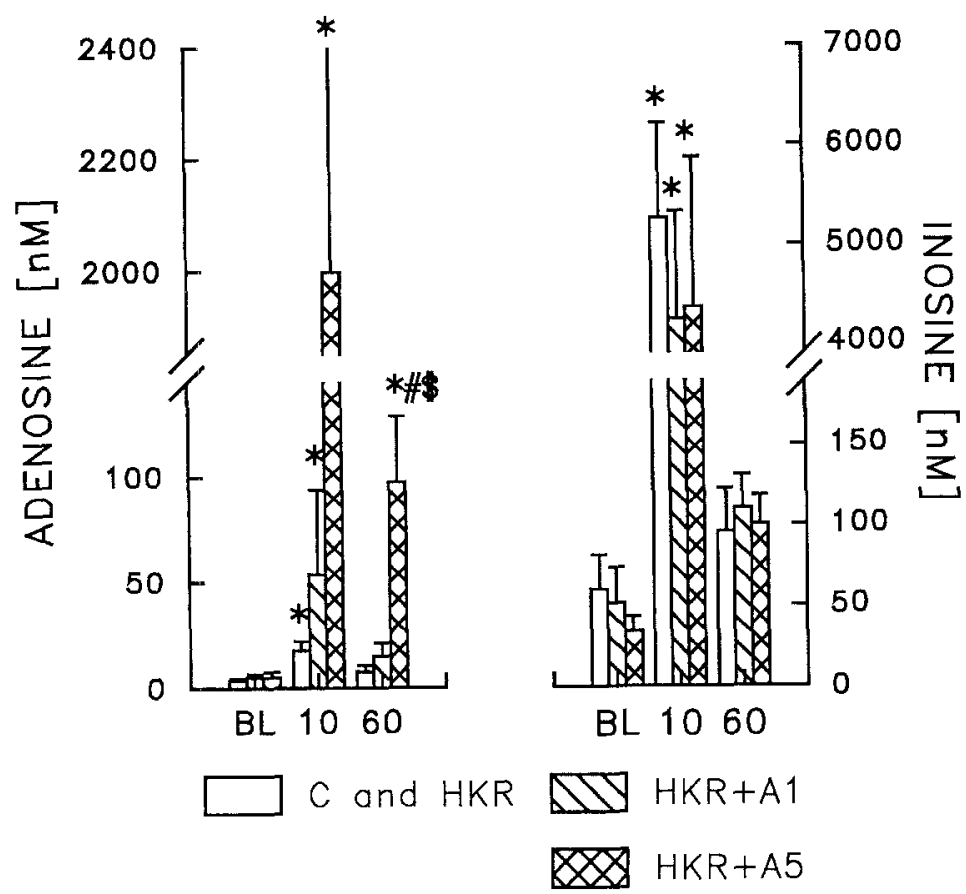

Fig. 5. Adenosine and inosine levels in coronary effluent at baseline before ischemia (BL) and at 10 minutes and 60 minutes of reperfusion. Data did not differ between control $(C)$ and HKR groups and were therefore pooled for statistical analyses. Inosine concentrations increased similarly in all groups at 10 minutes of reperfusion. Ischemia and reperfusion caused a moderate increase in the release of endogenous adenosine from control and HKR hearts groups at 10 minutes of reperfusion. Both concentrations of adenosine during initial HKR increased effluent adenosine levels after 10 minutes of reperfusion, but after 60 minutes of reperfusion adenosine remained elevated only in the $\mathrm{HKR}+\mathrm{A} 5$ group. Control, $n=3$; HKR, $n=2 ; \mathrm{HKR}+\mathrm{A} 1, n=5 ; \mathrm{HKR}+\mathrm{A} 5, n=5$. Means \pm standard error of the mean. Symbols indicate $p$ values: $*, p<0.05$ vs BL; \#, $p<0.05$ vs $\mathrm{C}$ and HKR; $\$, p<0.05$ vs HKR+A1.

adjusting osmolarity to normal, it is not entirely clear whether the observed beneficial effect of warm cardioplegic blood reperfusion was caused by cardioplegic arrest or rather by hyperosmolarity. In our isolated heart study, the osmolarity of the cardioplegic Krebs solution was adjusted to 300 mosm by reducing sodium chloride in exchange for the increase in potassium chloride. Improved LVDP, $\mathrm{dP} / \mathrm{dt}_{\max }$, and $-\mathrm{dP} / \mathrm{dt}_{\max }$ after HKR treatment clearly indicate that myocardial systolic and diastolic functions are both better preserved solely by HKR. Moreover, markedly improved myocardial function was achieved without the antioxidative capacity of whole blood, as in warm cardioplegic blood reperfusion, ${ }^{4,6,16}$ and also without pharmacologic free-radical scavengers. In our study, improved myocardial recovery with HKR is probably caused by reduced oxygen demand during initial reperfusion. At $37^{\circ} \mathrm{C}$, oxygen demand of the arrested and decompressed heart is reduced by $80 \%$ compared with the beating or fibrillating heart. ${ }^{16}$ Reduced demand may allow myocardial tissue to use the redelivered oxygen more efficiently for processes not associated with the output of mechanical work. ${ }^{6}$

If the improved oxygen balance is indeed crucial for the beneficial effects of HKR, then the wellknown vasoconstricting effect of elevated potassium chloride during HKR might limit the effectiveness of this therapy. Indeed, after ischemia and reperfusion, coronary flow during HKR without adenosine decreased to $45 \% \pm 3 \%$ of its preischemic baseline. The increased arterial-venous oxygen difference until 60 minutes of reperfusion in hearts in the HKR group demonstrates inadequate myocardial perfusion for oxygen demand and may indicate either more pronounced vascular damage (decreased oxygen delivery) or increased oxygen demand as a result of the enhanced metabolic demand.

These data allow two conclusions: (1) Because hyperkalemia reduces the coronary vascular conductance during and for several minutes after HKR, 
oxygen delivery to the myocardium is limited during HKR. (2) HKR may not have aggravated damage to the coronary vasculature, but rather may have increased the metabolic demand as function improved.

In previous experimental studies coronary flow during warm cardioplegic reperfusion was not well documented, and clinical studies investigating coronary vascular resistance during cardioplegic reperfusion remain inconclusive. ${ }^{8,9}$ We believe that if HKR did not limit oxygen supply, myocardial performance could be further improved. Various experimental studies have shown that vasodilators improve postischemic coronary flow and myocardial function well beyond the period of drug infusion. ${ }^{11,}$ 17-19

Among the various cardiac effects of adenosine, ${ }^{20}$

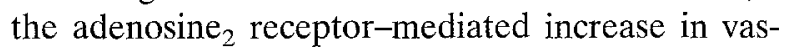
cular conductance and oxygen delivery may be the pivotal mechanism during reperfusion. ${ }^{11,17,18,21}$ The two tested concentrations of adenosine, $1 \mathrm{mmol} / \mathrm{L}$ and $5 \mathrm{mmol} / \mathrm{L}$, have been successfully used during hyperkalemic cardioplegic arrest. ${ }^{22,23}$ In our study, both concentrations (administered during HKR only) increased flow during initial HKR, but only $5 \mathrm{mmol} / \mathrm{L}$ adenosine resulted in sustained enhancement of coronary flow and myocardial function during the entire reperfusion period. Improvements in initial flow and oxygen delivery during initial reperfusion, which were equivalent for both adenosine concentrations, cannot be the pivotal mechanism of the sustained effects of 5 $\mathrm{mmol} / \mathrm{L}$ adenosine.

We can only speculate on the mechanisms of the beneficial effects of $5 \mathrm{mmol} / \mathrm{L}$ adenosine. Our data (Fig. 5) indicate that effective concentrations of adenosine were present in the myocardial tissue of hearts in the HKR + A5 group at 60 minutes of reperfusion. The subsequent vasodilation may have increased oxygen delivery and allowed better myocardial performance without affecting the mechanisms responsible for the depression of cardiac efficiency in converting oxygen to mechanical work. In a previous study from our laboratory ${ }^{15}$ washout of endogenously produced adenosine after ischemia and reperfusion in isolated hearts persisted for longer than 10 minutes but was complete after 40 minutes of reperfusion. This correlates well with our inosine and adenosine levels in the control, HKR, and $\mathrm{HKR}+\mathrm{A} 1$ groups, but it does not explain the elevated adenosine levels in HKR $+\mathrm{A} 5$ hearts after 60 minutes of reperfusion. The coronary vascular endothelium has a high metabolic rate for adenosine, ${ }^{24}$ which may explain why 5 minutes of 5 $\mathrm{mmol} / \mathrm{L}$ but not $1 \mathrm{mmol} / \mathrm{L}$ adenosine reperfusion could load the myocardial tissue with sufficient adenosine to delay complete washout of the drug for more than 1 hour. According to an alternative hypothesis, during high-dose adenosine reperfusion in the presence of abundant oxygen and energy substrates, some of the exogenously administered adenosine may be phosphorylated to produce adenosine triphosphate (ATP) in excess of energy demand. ${ }^{25}$ Such rapid ATP synthesis from exogenous adenosine was demonstrated in isolated cardiac muscle cells. ${ }^{26}$ After washout of exogenous adenosine, these intracellular ATP stores might be dephosphorylated to provide additional energy for enhanced cardiac function and release of adenosine for the observed flow increase.

None of the treatments tested in our study had any effect on the attenuated coronary reserve response during reperfusion (Fig. 4). While a bolus injection of adenosine increased flow by about $120 \%$ to $150 \%$ before ischemia in all groups, flow increases were only $26 \%$ to $34 \%$ over postischemic resting flow. Because endothelium-dependent (acetylcholine) and endothelium-independent (nitroprusside) vasodilators elicited similar significant flow responses, the postischemic depression of responses to both vasodilators indicates vascular smooth muscle damage rather than specific deterioration of endothelial function. ${ }^{24}$ Possibly perivascular edema limited the flow responses after reperfusion.

Although whole-animal experiments with blood as coronary perfusate are certainly much closer to the clinical setting, the isolated heart preparation allows control of preload and afterload factors, excludes neural and exocrine influences, and allows more precise on-line measurement of ventricular function indexes, coronary flow, and $\mathrm{MVO}_{2}$, thus providing useful data. We conclude that HKR for 5 minutes improves subsequent myocardial function, probably by reducing oxygen demand for electromechanical work during early reperfusion. Increasing flow during HKR by administering up to $1 \mathrm{mmol} / \mathrm{L}$ adenosine provides no sustained additional benefits for either coronary flow or myocardial function. In contrast, $5 \mathrm{mmol} / \mathrm{L}$ adenosine during 5 minutes of HKR improves flow and myocardial function for up to 60 minutes of reperfusion. Delayed washout of adenosine or accelerated resynthesis of ATP during HKR and subsequent dephosphorylation, with consequent prolonged adenosine ${ }_{1}$ receptor- and adenosine ${ }_{2}$ receptor-mediated effects beyond the period of adenosine-enriched HKR, may account for the beneficial 
effects of the higher dose of adenosine in our model. Although postischemic resting flow was improved in the HKR + A5 group after ischemia, the depression of coronary reserve was not affected by either IKK or adenosine.

\section{REFERENCES}

1. Follette DM, Steed DL, Foglia RP, Fey K, Buckberg GD. Reduction of postischemic myocardial damage by maintaining arrest during initial reperfusion. Surg Forum 1977;28:281-2.

2. Follette DM, Fey K, Buckberg GD, et al. Reducing postischemic damage by temporary modification of reperfusate calcium, potassium, $\mathrm{pH}$, and osmolarity. J Thorac CARdiovasC SuRg 1981;82:221-38.

3. Kofsky ER, Julia PL, Buckberg GD, Quillen JE, Acar C. Studies of controlled reperfusion after ischemia. XXII. Reperfusate composition: effects of leukocyte depletion of blood and blood cardioplegic reperfusates after acute coronary occlusion. J THORAC CARDIOVASC SURG 1991;101:350-9.

4. Julia PL, Buckberg GD, Acar C, Partington MT, Sherman MP. Studies of controlled reperfusion after ischemia. XXI. Reperfusate composition: superiority of blood cardioplegia over crystalloid cardioplegia in limiting reperfusion damage-importance of endogenous oxygen free radical scavengers in red blood cells. J Thorac Cardiovasc Surg 1991;101:303-13.

5. Acar C, Partington MT, Buckberg GD. Studies of controlled reperfusion after ischemia. XX. Reperfusate composition: detrimental effects of initial asanguineous cardioplegic washout after acute coronary occlusion. J ThoraC CardiovasC Surg 1991;101:294302.

6. Acar C, Partington MT, Buckberg GD. Studies of controlled reperfusion after ischemia. XIX. Reperfusate composition: benefits of blood cardioplegia over fluosol DA cardioplegia during regional reperfusion-importance of including blood components in the initial reperfusate. J THORAC CARDiovasc SuRG 1991;101:284-93.

7. Allen BS, Okamoto F, Buckberg GD, Bugyi H, Leaf J. Studies of controlled reperfusion after ischemia. XV. Immediate functional recovery after six hours of regional ischemia by careful control of conditions of reperfusion and composition of reperfusate. J THORaC Cardiovasc Surg 1986;92:621-35.

8. Digerness SB, Kirklin JW, Naftel DC, Blackstone EH, Kirklin JK, Samuelson PN. Coronary and systemic vascular resistance during reperfusion after global myocardial ischemia. Ann Thorac Surg 1988;46:44754.

9. Kirklin JK, Neves J, Naftel DC, Digerness SB, Kirklin JW, Blackstone EH. Controlled initial hyperkalemic reperfusion after cardiac transplantation: coronary vascular resistance and blood flow. Ann Thorac Surg 1990;49:625-31.

10. Stowe DF, Boban M, Graf BM, Kampine JP, Bosnjak ZJ. Contraction uncoupling versus low calcium or high potassium solutions on flow and contractile function of isolated hearts after prolonged hypothermic perfusion. Circulation 1994;89:2412-20.

11. Amrani M, Shirvani R, Allen NJ, Ledingham S, Yacoub MH. Enhancement of low coronary reflow improves postischemic myocardial function. J THORAC Cardiovasc Surg 1992;104:1375-82.

12. Stowe DF, Bosnjak ZJ, Marijic J, Kampine JP. Effects of halothane with and without histamine and/or epinephrine on automaticity, intracardiac conduction times, and development of dysrhythmias in the isolated guinea pig heart. Anesthesiology 1988;68:695706.

13. Smith VE, Zile MR. Relaxation and diastolic properties of the heart. In: Fozzard HA, Haber E, Jennings RB, Katz AM, Morgan HE, eds. The heart and cardiovascular system. 2nd ed. New York: Raven Press, 1992:1353-67.

14. Kaufman TM, Horton JW, White DJ, Mahony L. Age-related changes in myocardial relaxation and sarcoplasmic reticulum function. Am J Physiol 1990; 259(2 Pt 2):H309-16.

15. Buljubasic N, Stowe DF, Marijic J, Roerig DL, Kampine JP, Bosnjak ZJ. Halothane reduces release of adenosine, inosine, and lactate with ischemia and reperfusion in isolated hearts. Anesth Analg 1993;76: 54-62.

16. Buckberg GD. Myocardial temperature management during aortic clamping for cardiac surgery-protection, preoccupation, and perspective. J THORAC CARDiovasc SuRG 1991;102:895-903.

17. Ledingham S, Katayama O, Lachno D, Patel N, Yacoub M. Beneficial effect of adenosine during reperfusion following prolonged cardioplegic arrest. Cardiovasc Res 1990;24:247-53.

18. Stowe DF, Boban M, Kampine JP, Bosnjak ZJ. Reperfusion with adenosine and nitroprusside improves preservation of isolated guinea pig hearts after 22 hours of cold perfusion with 2,3 butanedione monoxime. J Cardiovasc Pharmacol 1993;21: 578-86.

19. Babbitt DG, Virmani R, Forman MB. Intracoronary adenosine administered after reperfusion limits vascular injury after prolonged ischemia in the canine model. Circulation 1989;80:1388-99.

20. Ely SW, Berne RM. Protective effects of adenosine in myocardial ischemia. Circulation 1992;85:893-904.

21. Janier MF, Vanoverschelde JLJ, Bergmann SR. Adenosine protects ischemic and reperfused myocardium by receptor-mediated mechanisms. Am J Physiol 1993;264(1 Pt 2):H163-70.

22. Stringham JC, Paulsen KL, Southhard JH, Mentzer 
RM, Belzer FO. Prolonging myocardial preservation with a modified University of Wisconsin solution containing 2,3-butanedione monoxime and calcium. J Thorac Cardiovasc Surg 1994;107:764-75.

23. de Jong JW, van der Meer P, van Loon H, Owen P, Opie LH. Adenosine as adjunct to potassium cardioplegia: effect of function, energy metabolism, and electrophysiology. J Thorac Cardrovasc Surg 1990;100:445-54.

24. Leipert B, Becker BF, Gerlach E. Different endothelial mechanisms involved in coronary responses to known vasodilators. Am J Physiol 1992;262(6 Pt 2): H1676-83.

25. Bolling SF, Bies LE, Bove EL. Effect of ATP synthesis promoters on postischemic myocardial recovery. J Surg Res 1990;49:205-11.

26. Rovetto MJ, Ford DA, Yassin A. Cardiac myocyte and coronary endothelial cell adenosine transport. In: Gerlach E, Becker BF, eds. Topics and perspectives in adenosine research. Berlin: Springer-Verlag, 1986: 188-98.

\section{ON THE MOVE?}

Send us your new address at least six weeks ahead

Don't miss a single issue of the journal! To ensure prompt service when you change your address, please photocopy and complete the form below.

Please send your change of address notification at least six weeks before your move to ensure continued service. We regret we cannot guarantee replacement of issues missed due to late notification.

\section{JOURNAL TITLE:}

Fill in the title of the journal here.

\section{OLD ADDRESS:}

Affix the address label from a recent issue of the journal here.

\section{NEW ADDRESS:}

Clearly print your new address here.

Name

Address

City/State/ZIP
COPY AND MAIL THIS FORM TO:

Journal Subscription Services

Mosby-Year Book, Inc.

11830 Westline Industrial Dr.

St. Louis, MO 63146-3318
OR FAX TO:

314-432-1158

NM Mosby
OR PHONE:

1-800-453-4351

Outside the U.S., call

314-453-4351 